\title{
Effect of Bonding Material, Etching Time and Silane on the Bond Strength of Metallic Orthodontic Brackets to Ceramic
}

\author{
Ana Rosa COSTA ${ }^{1}$ \\ Américo Bortolazzo CORRER ${ }^{1}$ \\ Regina Maria PUPPIN-RONTANI ${ }^{2}$ \\ Silvia Amélia VEDOVELLO ${ }^{3}$ \\ Heloísa Cristina VALDRIGHI ${ }^{3}$ \\ Lourenço CORRER-SOBRINHO ${ }^{1}$ \\ Mário VEDOVELLO FILHO ${ }^{3}$ \\ ${ }^{1}$ Department of Restorative Dentistry, Dental Materials Division, Piracicaba Dental School, \\ UNICAMP - University of Campinas, Piracicaba, SP, Brazil \\ ${ }^{2}$ Department of Pediatric Dentistry, Piracicaba Dental School, \\ UNICAMP - University of Campinas, Piracicaba, SP, Brazil \\ ${ }^{3}$ Department of Orthodontics, Graduate Program in Orthodontics, UNIARARAS - University of Araras, Araras, SP, Brazil

\begin{abstract}
The purpose of this study was to evaluate the bond strength of metallic orthodontic brackets to feldspathic ceramic with different etching times, bonding materials and with or without silane application. Cylinders of feldspathic ceramic were etched with $10 \%$ hydrofluoric acid for 20 or $60 \mathrm{~s}$. For each etching time, half of the cylinders received two layers of silane. Metallic brackets were bonded to the cylinders using Transbond XT (3M Unitek) or Fuji Ortho LC (GC). Light-activation was carried out with total exposure time of 40 $\mathrm{s}$ using UltraLume 5. Shear bond strength testing was performed after $24 \mathrm{~h}$ storage. Data were submitted to three-way ANOVA and Tukey's test $(\alpha=0.05)$. The adhesive remnant index (ARI) was used to evaluate the amount of adhesive remaining on the ceramic surface at $\times 8$ magnification. Specimens etched for $60 \mathrm{~s}$ had significantly higher bond strength compared with $20 \mathrm{~s}$. The application of silane was efficient in increasing the shear bond strength between ceramic and both fixed materials. Transbond XT showed significantly higher $(p<0.05)$ bond strength than Fuji Orth LC. There was a predominance of ARI score 0 (clean ceramic failure surface) for all groups, with an increase in scores 1, 2 and 3 (adhesive material increasingly present on ceramic failure aspect) for the 60-s etching time. In conclusion, 60-s etching time, silane and Transbond XT improved significantly the shear bond strength of brackets to ceramic.
\end{abstract}

Key Words: orthodontic bracket, ceramic, silane, acid etching.

\section{INTRODUCTION}

In certain clinical conditions, ceramics may serve as substrates for bonding orthodontic brackets. Bonding to ceramic is normally achieved after etching the ceramic surface with hydrofluoric acid. This etching procedure is used to create a rough surface in the ceramic bonding area to enhance the bond between bonding material and ceramic. However, the etching time required for optimal bonding to ceramic is controversial in the literature. Several authors showed decreased bond strengths with increasing etching times (1-3). On the other hand other authors (4-6) showed that extending etching times may increase the bond strength to ceramic.

In addition, the bond strength between brackets and ceramic surface may also be improved by the application of silanes, which are capable of forming chemical bonds with both inorganic and organic surfaces $(7,8)$. Several studies have shown increased bond strength when silane is used $(3,8-10)$.

After the acid treatment and silane application, the irregularities created on ceramic need to be infiltrated

Correspondence: Prof. Dr. Lourenço Correr-Sobrinho, Departamento de Dentística, Divisão de Materiais Odontológicos, Faculdade de Odontologia de Piracicaba, UNICAMP, Avenida Limeira, 901, 13414-903 Piracicaba, SP, Brasil. Tel: +55-19-2106-5345. Fax: +55-19-2106-5218. e-mail: sobrinho@fop.unicamp.br 
by a material for bonding. Composite resins are used to attach orthodontic brackets to enamel or ceramic surfaces. The protocol comprises a series of techniquesensitive steps and failures with composite resins have been attributed to moisture contamination (11). Other materials used to attach brackets to enamel or ceramic surfaces are resin-modified glass ionomer cements. They have cariostatic properties due to a slow release of fluoride at low levels over an extended period (12). However, it has been extensively demonstrated that glass ionomer cements are associated with significantly lower bond strength than composite resins $(13,14)$.

The purpose of this study was to evaluate the bond strength of metallic orthodontic brackets to feldspathic ceramic, using different etching times (20 or $60 \mathrm{~s}$ ) for etching ceramic, different bonding materials (Transbond XT and Fuji Ortho LC) with or without silane application. The hypotheses tested were that there is (1) no significant difference in shear bond strength between the two etching times, (2) no significant difference between with or without silane application, and (3) no significant difference between the bonding materials.

\section{MATERIAL AND METHODS}

Eight feldspathic ceramic (Certec Advanced Ceramics, Barueri, SP, Brazil) cylinders $(15 \mathrm{~mm}$ diameter x $20 \mathrm{~mm}$ height) were prepared and had their surfaces cleaned using pumice-water slurry (S.S. White, Petrópolis, RJ, Brazil). Four cylinders were etched using $10 \%$ hydrofluoric acid gel (Dentsply Caulk, Milford, DE, USA) for 20 and four for $60 \mathrm{~s}$. After etching, the ceramic surfaces were rinsed with air-water spray for $30 \mathrm{~s}$ and dried with an air stream for $30 \mathrm{~s}$. In half of the cylinders for each etching time, two layers of a silane coupling agent (RelyX Ceramic Primer; 3M ESPE, St. Paul, MN, USA) were applied and dried for $60 \mathrm{~s}$. After that, stainless steel standard maxillary incisor metallic orthodontic brackets (Synergy; Rocky Mountain Orthodontics, Denver, CO, USA) were bonded to the specimens using Transbond XT light-cured bonding resin (3M Unitek, Monrovia, CO, USA) or resin-modified glass ionomer Fuji Ortho LC (GC America Inc., Alsip, IL, USA), following the manufacturer's instructions.

The brackets were positioned and seated firmly on the ceramic surface. Excess resin was removed using a microbrush and light-activation was carried out with $10 \mathrm{~s}$ exposures on each of the four sides of the bracket. Total exposure time was $40 \mathrm{~s}$ using a LED curing unit
(UltraLume 5; Ultradent, South Jordan, UT, USA), emitting at $1,200 \mathrm{~mW} / \mathrm{cm}^{2}$. In total, 20 brackets were bonded to each ceramic cylinder $(\mathrm{n}=20)$ for each etching time - bonding resin/resin-modified glass ionomer silane combination, totaling a 160 bonded brackets. As several brackets $(n=20)$ were bonded to the same ceramic cylinder, a punch-holed strip of black adhesive tape was used to avoid light exposure to adjacent brackets, restricting the polymerization light to the specimen being bonded (5). Afterwards, the specimens were stored in distilled water at $37^{\circ} \mathrm{C}$ for $24 \mathrm{~h}$.

The shear bond strength test was conducted in a mechanical testing machine (Model 4411; Instron, Canton, MA, USA). A mounting jig was used to align the ceramic-bracket interface parallel to the testing device. The shear load was applied using a knife-edged rod at a crosshead speed of $1.0 \mathrm{~mm} / \mathrm{min}$ until failure occurred $(5,15)$. The shear bond strength values were calculated in MPa and subjected to three-way ANOVA and Tukey's test $(\alpha=0.05)$.

After debonding, the ceramic and bracket surfaces were examined under $\times 8$ magnification with a stereomicroscope (Olympus Corp., Tokyo, Japan). The Adhesive Remnant Index (ARI) modified after the method of Årtun and Bergland (16) was used to classify the failure modes: 0: indicates that no bonding resin or resin-modified glass ionomer remained on the ceramic; 1: indicates that less than half of the bonding resin or resin-modified glass ionomer remained on the ceramic; 2: indicates that more than half of the bonding resin or resin-modified glass ionomer remained on the ceramic; and 3: indicates that all bonding resin or resin-modified glass ionomer remained on the ceramic, along with a distinct impression of the bracket mesh.

\section{RESULTS}

The results for shear bond strength of brackets to ceramic are given in Table 1. The statistical analysis showed that regardless of bonding material and etching time, silane application increased bond strength significantly $(p<0.05)$ compared with no silane application. The bonding material Transbond XT promoted a significantly higher $(\mathrm{p}<0.05)$ shear bond strength than Fuji Ortho LC, with or without silane application and for both etching times. The specimens etched for $20 \mathrm{~s}$ showed significantly lower $(\mathrm{p}<0.05)$ shear bond strengths than those etched for $60 \mathrm{~s}$, for both bonding materials. 
The results for ARI are shown in Table 2. A predominance of score 0 was observed for specimens etched for $20 \mathrm{~s}$, independent of bonding material or silane application. On the other hand, despite the large number of scores 0 observed for the specimens etched for $60 \mathrm{~s}$, there was an increase in scores 1,2 and 3 for the longer etching time.

\section{DISCUSSION}

In this study, the first hypothesis tested was rejected. An increase in shear bond strength was observed for specimens etched with $10 \%$ hydrofluoric acid for 60 $\mathrm{s}$ compared with $20 \mathrm{~s}$, regardless of the bonding material.

Efficient bonding to ceramic is determined by the bonding mechanisms that are controlled in part by the specific surface treatment used to promote micromechanical or chemical retention to the ceramic substrate (17). The micromechanical retention of the ceramic surface plays an important role for bonding with resin cement (8). Modification of ceramic surface morphology may be performed to increase bond strength (18). According to Yen et al. (19), hydrofluoric acid starts etching the ceramic by reacting preferentially with the silica phase, creating retentive microchannels. With time, the acid reacts with the glassy matrix, partially dissolving it and increasing the formation of retentive channels. The morphological changes produced on surfaces treated with $10 \%$ hydrofluoric acid increase the surface area and facilitates the penetration and retention of resin cement into the created micro-retentions $(8,18,20)$. Therefore, longer etching times with $10 \%$ hydrofluoric acid on feldspathic ceramic surface may create more irregularities for bonding, explaining the results of the

Table 1. Mean shear bond strength values (S.D.) in MPa.

\begin{tabular}{lcccc}
\hline Treatment & $\begin{array}{c}\text { Etching } \\
\text { time }\end{array}$ & Transbond XT & $\begin{array}{c}\text { Fuji Ortho } \\
\text { LC }\end{array}$ & $*$ \\
\hline With & $20 \mathrm{~s}$ & $11.61(1.3)^{\mathrm{A}, \mathrm{b}}$ & $7.62(1.2)^{\mathrm{B}, \mathrm{b}}$ & \\
silane* & $60 \mathrm{~s}$ & $13.81(1.4)^{\mathrm{A}, \mathrm{a}}$ & $9.63(1.3)^{\mathrm{B}, \mathrm{a}}$ & $\mathrm{A}$ \\
& $20 \mathrm{~s}$ & $9.81(1.1)^{\mathrm{A}, \mathrm{b}}$ & $5.75(0.9)^{\mathrm{B}, \mathrm{b}}$ & \\
Without & $60 \mathrm{~s}$ & $11.60(1.1)^{\mathrm{A}, \mathrm{a}}$ & $7.70(1.7)^{\mathrm{B}, \mathrm{a}}$ & $\mathrm{B}$ \\
silane* & & & \\
\hline
\end{tabular}

Means followed by different uppercase letters in the same row and lowercase letters in the same column indicate statistically significant difference $(\mathrm{p}<0.05)$. * Comparison for with or without silane application independent of the bonding material and etching time, with different uppercase letters indicating statistically significant difference $(\mathrm{p}<0.05)$. present study.

Reynolds (21) suggested that a bond strength value between 6.0 to $8.0 \mathrm{MPa}$ was adequate for most clinical orthodontic needs in the oral environment. In this study, bond strength values lower than 6.0 MPa were detected only for one group in which the ceramic surfaces were etched for $20 \mathrm{~s}$ and bonded with Fuji Ortho LC without previous silane application. Therefore, 20 s etching time with $10 \%$ hydrofluoric acid application might be insufficient for creating retention for proper bonding of orthodontic brackets with Fuji Ortho LC to feldspathic ceramic without silane application and resist forces during orthodontic treatment.

Another factor evaluated in this study was the influence of silane on the shear bond strength between orthodontic brackets and bonding materials. Silane coupling agents are usually monomeric species in which silicon is linked to reactive organic radicals and hydrolyzable ester groups. The reactive organic groups become chemically bonded to the resin molecules. Hydrolyzable monovalent groups bond chemically to silicon contained in the glass matrix and lithium disilicate crystals $(8,22)$. Then, a chemical bond is formed between the silane coupling agent and silica layer on the ceramic surface or the bonding materials.

Table 2. Frequency distributions (\%) of the Adhesive Remnant Index (ARI) scores.

\begin{tabular}{|c|c|c|c|c|c|c|}
\hline \multirow{2}{*}{ Treatment } & \multirow{2}{*}{$\begin{array}{l}\text { Bonding } \\
\text { material }\end{array}$} & \multirow{2}{*}{$\begin{array}{c}\text { Etching } \\
\text { time }\end{array}$} & \multicolumn{4}{|c|}{ ARI Scores* (\%) } \\
\hline & & & 0 & 1 & 2 & 3 \\
\hline \multirow{2}{*}{$\begin{array}{l}\text { With } \\
\text { silane }\end{array}$} & \multirow{2}{*}{$\begin{array}{c}\text { Transbond } \\
\text { XT }\end{array}$} & $20 \mathrm{~s}$ & 86.7 & 13.3 & - & - \\
\hline & & $60 \mathrm{~s}$ & 73.4 & 13.3 & 13.3 & - \\
\hline \multirow{2}{*}{$\begin{array}{l}\text { Without } \\
\text { silane }\end{array}$} & \multirow{2}{*}{$\begin{array}{c}\text { Transbond } \\
\text { XT }\end{array}$} & $20 \mathrm{~s}$ & 66.7 & 26.6 & - & 6.7 \\
\hline & & $60 \mathrm{~s}$ & 46.6 & 40 & 6.7 & 6.7 \\
\hline \multirow{2}{*}{$\begin{array}{l}\text { With } \\
\text { silane }\end{array}$} & Fuji & $20 \mathrm{~s}$ & 100 & - & - & - \\
\hline & Ortho LC & $60 \mathrm{~s}$ & 60 & 20 & 6.7 & 13.3 \\
\hline \multirow{2}{*}{$\begin{array}{l}\text { Without } \\
\text { silane }\end{array}$} & Fuji & $20 \mathrm{~s}$ & 100 & - & - & - \\
\hline & Ortho LC & $60 \mathrm{~s}$ & 53.4 & 26.6 & 13.3 & 6.7 \\
\hline
\end{tabular}

*The ARI scoring system has a range between 0 and 3 , with 0 indicating that no bonding resin or resin-modified glass ionomer remained on the ceramic; 1 : less than half of the bonding resin or resin-modified glass ionomer remained on the ceramic; 2 : more than half of the bonding resin or resin-modified glass ionomer remained on the ceramic; and 3: indicates all bonding resin or resin-modified glass ionomer remained on the ceramic, along with a distinct impression of the bracket mesh. 
The second hypothesis tested was also rejected. The present study showed that independent of the acid etching time and bonding materials, there was always an increase in the shear bond strength for the groups that received silane application, which is in accordance with previous studies $(3,8-10)$.

Transbond XT produced significantly higher shear bond strength than Fuji Ortho LC in all tested conditions, and thus the third hypothesis was also rejected. Despite the brackets having been fixed on ceramic surface, these findings are in agreement with those of previous studies that reported lower shear bond strength for Fuji Ortho LC than Transbond XT, when brackets were bonded to enamel surface using these materials $(13,14)$. However, other studies reported that the shear bond strength for Fuji Ortho LC was not statistically different from Transbond XT when bonded to enamel (22-24).

The difference between two bonding materials can be related to differences in viscosity and composition. Fuji Ortho LC showed less flow than Transbond XT, probably due to the presence glass particles, which may reduce the effect of wetness for this material on ceramic surface. Bond strength values between 6 to $8 \mathrm{MPa}$ have been recommended (21). Based on this recommendation, bracket bonding to ceramic with Fuji Ortho LC using the protocol of 20 -s etching with $10 \%$ hydrofluoric acid without previous silanization does not have the potential to resist forces during orthodontic treatment, as a shear bond strength of only 5.75 MPa was obtained.

The ARI scores showed that most failures after debonding were scored 0 , with no bonding resin or resin-modified glass ionomer remaining on the ceramic surface. This may be clinically advantageous because there is less adhesive to remove from the ceramic surface after debonding. The increase in ARI scores 1, 2 and 3 for the 60 -s etching time probably occurred due to the increased retention created on the ceramic surface. Therefore, the increased mechanical interlocking of the bonding resin or resin-modified glass ionomer to ceramic generates failures involving both bonded materials, and not only adhesive failures. This finding is in agreement with those of a previous study that reported that shorter etching times might affect not only the bond strengths of brackets to ceramic, but also the mode of failure to the bonding substrate (5).

In summary, the present study demonstrated that etching time and silane application is a decisive factor for the bond strength of brackets to ceramic surfaces. Although clinicians follow the manufacturers' instructions for bonding procedures, a 60 s etching time and silane application for bonding to ceramic might be recommended. On the other hand, care should be taken to select the right etching time for a ceramic surface. Some studies have shown negative effects of over-etching ceramics, attributed to difficulties of the bonding materials to penetrate into the irregularities and the potential for cohesive failure of the substrate $(1-4,25)$. In spite of the stronger shear bond strength found for the Transbond XT, the results of this study suggest that Fuji Ortho LC can be used under the tested conditions, except for the $20 \mathrm{~s}$ etching time with $10 \%$ hydrofluoric acid without silane application on ceramic surface. Therefore, clinicians need to take the specific properties of bonding materials into consideration and should be careful during clinical application of hydrofluoric acid.

\section{RESUMO}

O objetivo neste estudo foi avaliar a resistência de união de bráquetes a cerâmica feldspática com diferentes tempos de condicionamento ácido, materiais de união, com ou sem aplicação do silano. Cilindros de cerâmica feldspática foram condicionados com ácido fluorídrico $10 \%$ por 20 ou 60 s. Para cada tempo de condicionamento, metade dos cilindros recebeu duas camadas de silano. Bráquetes metálicos foram fixados aos cilindros utilizando Transbond XT (3MUnitek) ou Fuji Ortho LC (GC). A fotoativação foi realizada com tempo de exposição total de $40 \mathrm{~s}$ utilizando LED UltraLume 5. O ensaio de resistência ao cisalhamento foi realizado após $24 \mathrm{~h}$ de armazenagem. Os dados foram submetidos à Análise de Variância a três fatores e teste de Tukey $(\alpha=0,05)$. O Índice de Remanescente Adesivo (IRA) foi utilizado para avaliar a quantidade de adesivo remanescente na superfície cerâmica com magnificação de $8 \times$. Os espécimes condicionados por $60 \mathrm{~s}$ apresentaram maior resistência de união comparado com $20 \mathrm{~s}$. A aplicação do silano foi efetiva no aumento da resistência de união ao cisalhamento de bráquetes com a cerâmica para ambos os materiais. O Transbond XT mostrou resistência de união significativamente maior que Fuji Orth LC. O IRA mostrou predominância de escore 0 (ausência de resina na superfície cerâmica) para todos os grupos, com aumento de escores 1,2 e 3 (aumento da presença de resina na superfície cerâmica) para o tempo de condicionamento de $60 \mathrm{~s}$. Em conclusão, o tempo de condicionamento de $60 \mathrm{~s}$, aplicação de silano e resina Transbond XT melhoraram significativamente a resistência de união ao cisalhamento de bráquetes a cerâmica feldspática.

\section{REFERENCES}

1. Barghi N, Fischer DE, Vatani L. Effects of porcelain leucite content, types of etchants, and etching time on porcelaincomposite bond. J Esthet Restor Dent 2006;18:47-52; discussion 53.

2. Nagayassu MP, Shintome LK, Uemura ES, Araujo JE. Effect of surface treatment on the shear bond strength of a resin-based 
cement to porcelain. Braz Dent J 2006;17:290-295.

3. Shimada Y, Yamaguchi S, Tagami J. Micro-shear bond strength of dual-cured resin cement to glass ceramics. Dent Mater 2002; 18:380-388.

4. Chen JH, Matsumura $\mathrm{H}$, Atsuta M. Effect of different etching periods on the bond strength of a composite resin to a machinable porcelain. J Dent 1998;26:53-58.

5. Gonçalves PR, Moraes RR, Costa AR, Correr AB, Nouer PR, Sinhoreti MA, et al.. Effect of etching time and light source on the bond strength of metallic brackets to ceramic. Braz Dent $\mathrm{J}$ 2011;22:245-248.

6. Guler AU, Yilmaz F, Yenisey M, Guler E, Ural C. Effect of acid etching time and a self-etching adhesive on the shear bond strength of composite resin to porcelain. J Adhes Dent 2006;8:21-25.

7. Novais VR, Simamotos Junior PC, Rontani RM, Correr-Sobrinho L, Soares CJ. Bond strength between fiber posts and composite resin core: influence of temperature on silane coupling agents. Braz Dent J 2012;23:8-14.

8. Spohr AM, Sobrinho LC, Consani S, Sinhoreti MA, Knowles JC. Influence of surface conditions and silane agent on the bond of resin to IPS Empress 2 ceramic. Int J Prosthodont 2003;16:277282.

9. Brentel AS, Ozcan M, Valandro LF, Alarca LG, Amaral R, Bottino MA. Microtensile bond strength of a resin cement to feldpathic ceramic after different etching and silanization regimens in dry and aged conditions. Dent Mater 2007;23:1323-1331.

10. Kitayama S, Nikaido T, Takahashi R, Zhu L, Ikeda M, Foxton RM, et al.. Effect of primer treatment on bonding of resin cements to zirconia ceramic. Dent Mater 2010;26:426-432.

11. Zachrisson BJ. A posttreatment evaluation of direct bonding in Orthodontics. Am J Orthod 1977;71:173-189.

12. Christensen GJ. Dental cements: are they the weak link? J Am Dent Assoc 1991;122:63-64.

13. Bishara SE, Vonwald L, Laffoon JF, Jakobsen JR. Effect of altering the type of enamel conditioner on the shear bond strength of a resin-reinforced glass ionomer adhesive. Am J Orthod Dentofacial Orthop 2000;118:288-294.

14. Correr-Sobrinho L, Correr GM, Consani S, Sinhoreti MA, Consani RL. Influence of post-fixation time on shear bond strength of brackets fixed with different materials. Braz Oral Res 2002;16:4349.

15. Costa AR, Correr AB, Puppin-Rontani RM, Vedovello SA, Valdrighi HC, Correr-Sobrinho L, et al.. Effects of thermocycling and light source on the bond strength of metallic brackets to bovine teeth. Braz Dent J 2011;22:486-489.

16. Artun J, Bergland S. Clinical trials with crystal growth conditioning as an alternative to acid-etch enamel pretreatment. Am J Orthod 1984;85:333-340.

17. Della Bona A, Shen C, Anusavice KJ. Work of adhesion of resin on treated lithia disilicate-based ceramic. Dent Mater 2004;20:338 344.

18. Salvio LA, Correr-Sobrinho L, Consani S, Sinhoreti MA, de Goes MF, Knowles JC. Effect of water storage and surface treatments on the tensile bond strength of IPS Empress 2 ceramic. J Prosthodont 2007;16:192-199.

19. Yen TW, Blackman RB, Baez RJ. Effect of acid etching on the flexural strength of a feldspathic porcelain and a castable glass ceramic. J Prosthet Dent 1993;70:224-233.

20. Ozcan M, Vallittu PK. Effect of surface conditioning methods on the bond strength of luting cement to ceramics. Dent Mater 2003; 19:725-731.

21. Reynolds IR. A review of direct orthodontic bonding. Br J Orthod $1975 ; 2: 171-178$.

22. Chung CH, Cuozzo PT, Mante FK. Shear bond strength of a resinreinforced glass ionomer cement: an in vitro comparative study. Am J Orthod Dentofacial Orthop 1999;115:52-54.

23. Bishara SE, Olsen ME, Damon P, Jakobsen JR. Evaluation of a new light-cured orthodontic bonding adhesive. Am J Orthod Dentofacial Orthop 1998;114:80-87.

24. Lippitz SJ, Staley RN, Jakobsen JR. In vitro study of 24-hour and 30-day shear bond strengths of three resin-glass ionomer cements used to bond orthodontic brackets. Am J Orthod Dentofacial Orthop 1998;113:620-624.

25. Sant'Anna EF, Monnerat ME, Chevitarese O, Stuani MB. Bonding brackets to porcelain - in vitro study. Braz Dent J 2002;13:191-196.

Received October 8, 2011

Accepted May 22, 2012 